\title{
Differential scanning calorimetry reveals that whole-body cryostimulation in cross-country skiers can modify their response to physical effort
}

\author{
Anna Michnik ${ }^{1}$ ( Ilona Pokora ${ }^{2} \cdot$ Klaudia Duch $^{1} \cdot$ Ewa Sadowska-Krępa $^{2}$
}

Received: 12 March 2019 / Accepted: 3 January 2020 / Published online: 14 January 2020

(c) The Author(s) 2020

\begin{abstract}
In sport medicine, cryostimulation is used to help athletes to better support the training workload, to prevent the deleterious effects of strenuous exercise and to improve recovery. In this study, eight elite cross-country skiers had two experimental exercise sessions differing in that the second one was carried out after a series of 10 whole-body cryostimulation (WBC) treatments. Differential scanning calorimetry (DSC) was applied to compare changes in athlete's blood serum during both sessions. Mean DSC curves of serum collected in four stages of the training session: before exercise, after exercise, at $1 \mathrm{~h}$ recovery and after $24 \mathrm{~h}$ of rest have shown a similar nature of post-exercise changes and recovery regardless of the WBC. Statistically significant effect of the exercise, reflected in some parameters of serum denaturation transition, has been found. Too small number of participants in our study did not allow to verify the hypothesis that WBC favorably modifies athletes' reaction to the effort and improves post-exercise recovery, but such trends emerged.
\end{abstract}

Keywords DSC $\cdot$ Exercise $\cdot$ Human blood serum $\cdot$ Whole-body cryostimulation

\section{Introduction}

Whole-body cryotherapy was initially intended as a treatment for several diseases, e.g. rheumatoid arthritis, fibromyalgia and ankylosing spondylitis. Recently, this treatment covers a wide range of therapeutic applications. In contrast to cryotherapy, where a therapeutic aim is emphasized, the term "cryostimulation" is increasingly often used to highlight the stimulatory effect of cryogenic temperatures. It has gained popularity, particularly among athletes, as a recovery strategy following different sports activities. The cryostimulation has been employed by elite and recreational athletes to attenuate the negative impact of strenuous physical activity on subsequent exercise. The anti-inflammatory

Anna Michnik

anna.michnik@us.edu.pl

1 Faculty of Science and Technology, The Silesian Centre for Education and Interdisciplinary Research, University of Silesia in Katowice, ul. 75 Pułku Piechoty 1A, 41-500 Chorzów, Poland

2 The Jerzy Kukuczka Academy of Physical Education in Katowice, Institute of Sport Sciences, ul. Mikołowska 72a, 40-065 Katowice, Poland and analgesic effects of WBC are the most searched for by athletes and patients. Recent studies have confirmed these and other beneficial effects of extremely low temperatures in athletes [1-8].

In cold stress, heat loss is prevented by peripheral vasoconstriction (reflex cutaneous vasoconstriction) and heat production implemented by shivering and uncoupled mitochondrial activity $[9,10]$. Acute cold exposure causes powerful autonomic homoostatic responses in order to prevent heat loss and to maintain core body temperature. Cutaneous vasoconstriction and shivering thermogenesis are most important and are particularly powerful responses when both superficial and deep thermoreceptors are cooled simultaneously [11].

In contrast to acute responses, long-term adjustments require altered cellular functions, which are the basis of optimized performance of organs and the entire organism, and which include altered regulation of metabolic pathways as well as altered gene and protein expression. It is possible that a series of sessions of whole-body cold exposure may lead to the activation of antioxidant defense mechanisms in the body [12-16].

Most studies investigated the effect of WBC on functional recovery from exercise-induced muscle damage. Purnot 
et al. [17] compared recovery using WBC treatments to passive recovery, and they found that WBC significantly decreased inflammatory cytokines and increased levels of anti-inflammatory cytokines compared to passive recovery. Other studies reported that the regular use of cryostimulation after training may lead to easier muscle fiber repair as well as a decrease of a creatine kinase (CK) activity in blood serum $[4,18,19]$. Unlike these studies, both Hausswirth [20] and Fonda [21] found no significant changes in CK with protocols using either three or six exposures to WBC, respectively.

The effect of only single WBC intervention prior to exercise on parameters of oxidative and inflammatory responses was studied by Mila-Kierzenkowska et al. [22]. Their results allow to conclude that the magnitude of exercise-induced oxidative stress may be partly reduced even by single session of WBC applied prior to the submaximal exercise. Pournot et al. [17] reported that a single exposure to WBC significantly alleviated inflammation after a strenuous exercise run. They observed also reduced CRP-levels $24 \mathrm{~h}$ after one session of WBC compared to passive recovery in equally trained participants. In contrast to these findings, the results of the recent Krueger et al. study [23] have shown that WBC following high-intensity intermittent exercise did not alter hormonal, inflammatory or muscle damage biomarkers in trained males. Costello reported that there was no significant change in pain measurements during recovery with WBC [24]. The results obtained by Vieira et al. [25] indicate that one session of WBC had no effect on vertical jump following a high-intensity exercise compared with a control condition. According to Wilson's et al. [26] findings, WBC was no more effective than a placebo intervention at improving functional recovery or perceptions of training stress following a marathon. In their meta-analysis, Costello et al. [27] did not have sufficient evidence to recommend WBC for preventing muscle soreness.

Thus, despite its widespread adoption in sport and exercise medicine, it remains a moot point as to whether WBC treatments improve recovery and have a beneficial effect on athletic performance. The topic of post-exercise recovery from training has been the focus of recent attention in systematic reviews $[1,5,27-29]$. Possibilities to facilitate the recovery process after exercise and the physical, psychological and physiological effects of WBC can probably depend, among others on the type of sport being practiced. The interaction between sport-specific skill performance, the training load, subsequent fatigue and adaptation is complex and may be modulated (positively or negatively) by the recovery strategy [30].

In eccentric exercise metabolic demand, $\mathrm{VO}_{2}$ and blood lactate production are lower than during concentric exercise at similar muscle mechanical tension [31-33]. Skeletal muscles appear to be injured by exercise that involved lengthening contractions as eccentric activity [34]. In contrast to eccentric exercise, high-intensity concentric muscle contractions lead to metabolic stress of the exercising muscles, and short, temporary muscle fatigue but no to significant muscle damage [35, 36]. During dynamic exercise, the muscle performs both concentric and eccentric actions; however, different models of exercises might presumably induce the same degree of inflammatory effects whereby the degree of affect appears to be related to exercise duration, intensity and muscle mass involved to the mechanical work. Research objects in our work are cross-country skiers. The cross-country skiing is a relatively complex, demanding endurance sport involving several different, rapidly developing sub-techniques. It involves upper-, lower- or whole-body exercise to improve performance and endurance capacities. The associated demands require regular scientific evaluation in order to provide both coaches and skiers with the basic "tools" necessary for the development of optimal training programs.

Recovery implies the application of diverse procedures that can enable the quick regeneration of athletes and the reestablishment of homeostasis, which the previous exertion has disturbed. Main functions of recovery are as follows: normalization of biological functions in an athlete's organism, normalization of the homeostatic balance and restoration of energy supply reserves with the establishment of temporary supercompensation. In sports medicine, WBC is used to improve recovery from muscle injury. In present work, we were interested in whether the application of 10 WBC treatments can prevent the onset of overload and overtraining and would have an effect on the plasma proteome. Such empirical studies are lacking.

In this study, an unconventional approach was used to examine the influence of WBC treatments on the response of elite cross-country skiers to the physical effort and on recovery of athletic performance following exercise. The differential scanning calorimetry (DSC) method has been employed to compare changes in DSC profiles of blood sera in the same stages of the training cycle in two sessions. The first exercise session was carried out without cryostimulation. The second session took place after $10 \mathrm{WBC}$ treatments. So, to evaluate the effect of WBC, sera from the same athletes were tested twice in 4 stages: before exercise, after exercise, after $1 \mathrm{~h}$ and after $24 \mathrm{~h}$ of passive recovery.

The utility of DSC method for clinical application (diagnosing, classifying and monitoring patients) and in sport medicine is extensively discussed by scientists in recent years [37-55]. DSC has been widely applied to the analysis of blood plasma, serum or other biofluids to obtain information on the health status of the person examined. This technique allows to monitor heat capacity changes associated with the thermal denaturation of biomolecules. A DSC profile of plasma/serum reflects the global denaturation 
profile for all proteins present in the sample. It is sensitive to the up- or down-regulation of proteins and the modified thermal stability of major proteome components resulting from changes in interactions between blood plasma/serum proteins and disease-related metabolites. Earlier data from our laboratory have indicated that exercise training can also modulate the calorimetric profile of blood serum [53-55].

\section{Materials and methods}

\section{Participants}

The well-trained 8 cross-country skiers $(2$ women and 6 men) took part in our experiment during the transition period (TP) of the annual training cycle. During TP, the cross-country skiers were subjected to strict control regarding their diet, exercise and recovery by the team of trainers, that is, coaches, a physician, and two sport dieticians. The main characteristics of the cross-country skiers are presented in Table 1. The athletes performed specialized physical training. In cross-country skiers, the annual training plan is traditionally divided on three main macrocycles: preparatory, competitive and transition periods. Such plan is based

Table 1 Characteristics of participants

\begin{tabular}{lcl}
\hline & Before WBC & After 10 WBC sessions \\
\hline Age/year & $22.8 \pm 2.9$ & $22.8 \pm 2.9$ \\
Height $/ \mathrm{cm}$ & $176.6 \pm 10.9$ & $176.6 \pm 10.9$ \\
Body mass $/ \mathrm{kg}$ & $73.7 \pm 9.7$ & $73.5 \pm 9.4$ \\
Body fat mass $/ \mathrm{kg}$ & $9.3 \pm 2.9^{*}$ & $8.2 \pm 3.6^{*}$ \\
Body fat mass/\% & $13.1 \pm 5.8^{* *}$ & $11.8 \pm 6.7^{* *}$ \\
Skeletal muscle mass $/ \mathrm{kg}$ & $36.8 \pm 7.1$ & $37.3 \pm 7.4$ \\
$\mathrm{VO}_{2} \mathrm{max} / \mathrm{mL} \mathrm{min} \mathrm{kg}^{-1}$ & $60.1 \pm 8.4$ & n.a. \\
\hline
\end{tabular}

Values are means $\pm \mathrm{SD}$; statistically significant differences: $* p=0.02$, $* * p=0.03$ on the concept of periodization, which has to be viewed as an important concept to follow maximize athletes' performance. This study was performed during the transient phase of the annual training program (during the regeneration microcycle). Description of the training structure (training volume and distribution of workout intensities) in the transition phase of the annual training program for cross-country skiers (the athletes in our study) is presented in Table 2.

\section{Preliminary test for the determination of $\mathrm{VO}_{2} \max$ and individual anaerobic threshold}

One week prior to the start of the experiment body composition, aerobic fitness (maximal oxygen uptake, $\mathrm{VO}_{2} \max$ ) and individual anaerobic threshold (AT) were determined for each participant. Physiological variables, such as $\mathrm{VO}_{2} \mathrm{max}$, together with other submaximal metabolic inflection points (e.g. the anaerobic threshold) are quantified by sports scientists during an incremental exercise test to exhaustion (GXT). These variables have been shown to correlate with endurance performance. All competitors reported to the physical testing laboratory for an incremental running test on a treadmill (LE 200, Jaeger) to assess anaerobic threshold and peak oxygen uptake $\left(\mathrm{VO}_{2} \mathrm{max}\right)$ using a stationary breath-by-breath metabolic unit (MetaLyzer 3B-R2, Cortex). The exercise test started with a speed of $6 \mathrm{~km} \mathrm{~h}^{-1}$ that was increased by $2 \mathrm{~km} \mathrm{~h}^{-1}$ every 3 min until the speed reached $14 \mathrm{~km} \mathrm{~h}^{-1}$. Exercise intensity was then increased by adjusting treadmill incline by $2.5 \%$ every 3 min until subject's volitional exhaustion [56]. The lactate threshold was determined by the D-max method [57]. During GXT test, heart rate (HR), oxygen uptake $\left(\mathrm{VO}_{2}\right)$ and blood lactate concentration were recorded. HR corresponded to exercise intensity at AT was determined (HR-AT). HR-AT was used to appropriate exercise intensity estimation, which was accordingly used during experimental tests. The study was approved by the Research Ethics Committee at the Academy of Physical Education in Katowice, Poland.

Table 2 Description of the transition phase of the annual training plan

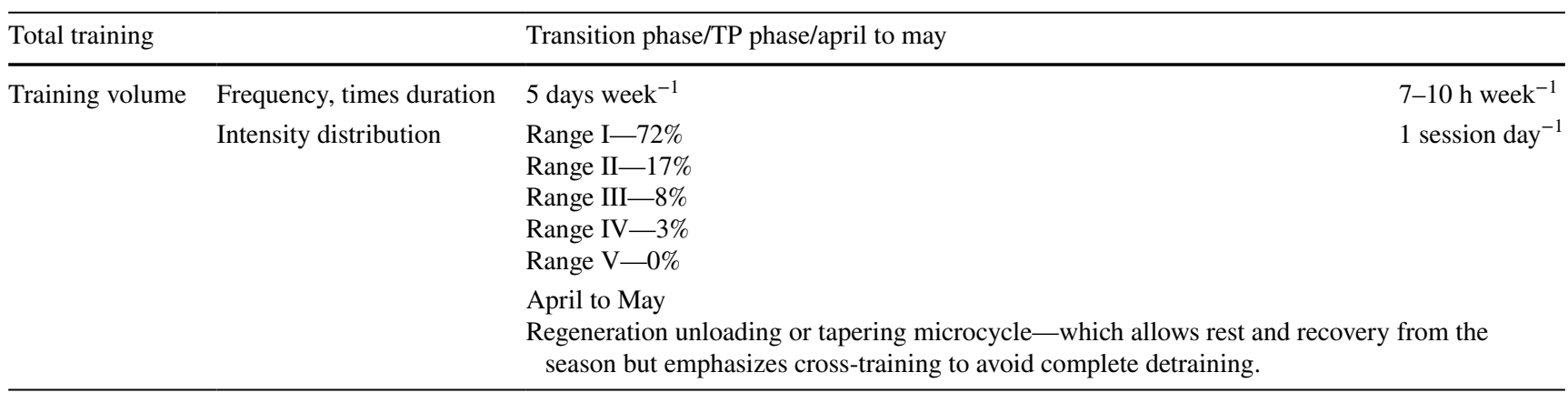

Intensity zones were used for description of workout intensities: I-low-aerobic/active recovery; II-moderate; III-moderate-intensity; IV-vigorousintensity, submaximal; V-maximal-intensity 


\section{Experimental exercise test (EET test)}

The main physical effort used in these studies was $1 \mathrm{~h}$ of uninterrupted running exercise (EET) performed in thermoneutral conditions. The participants performed continuous EET test twice, before and after a series of $10 \mathrm{WBC}$. The EET test was performed at predetermined intensity, below HR-AT for $60 \mathrm{~min}$. Two similar exercise tests, at a given intensity, were allowed to determine subjects' response to similar physical efforts before and after WBC therapy. During these exercise tests, subjects kept the steady speed of run, corresponding to $85-88 \%$ of HR-AT. All exercise tests were performed in Research Center for Sports, Academy of Physical Education in Katowice under thermoneutral environmental conditions (an ambient temperature $21-24{ }^{\circ} \mathrm{C}$ and a relative humidity $45-55 \%$ ) at the same time of day (8.00-14.00) to minimize the circadian rhythm effects, before and after of $10 \mathrm{WBC}$ treatments.

\section{Whole-body cryostimulation procedure}

Prior to the start of the experiment, each participant was examined by a physician to test for any contraindications against cryostimulation. Cryostimulation was performed in a cryo-chamber located in Upper Silesian Center of Medicine and Rehabilitation in Katowice. The treatment sessions were performed at temperature $-130{ }^{\circ} \mathrm{C}$ once a day for 10 following days, excluding Saturdays and Sundays. Each session of whole-body cryostimulation lasted $3 \mathrm{~min}$. The cryostimulation treatments took place at the same time, between $2 \mathrm{pm}$ and $6 \mathrm{pm}$. The subjects entered the chamber in groups of five persons. Entry to the cryo-chamber was preceded by a 30 -s adaptation period in the vestibule at a temperature of $-60{ }^{\circ} \mathrm{C}$, from which the subjects went further to the proper chamber, where they moved slowly in a circle, one after the other, without mutual contact, no additional movement or talking. After a minute, a change in the direction of motion was recommended. Contact with the participants was maintained via a camera in the room and voice contact.

\section{Blood serum}

Venus blood samples from the antecubital vein were drawn into tubes without anticoagulant at four time points: at rest (before the exercise-"be"), 3 min after the exercise ("ae"), after $1 \mathrm{~h}$ ("r1h") and again $24 \mathrm{~h}$ ("r24h") of recovery to process for serum. Serum samples were stored at $-20{ }^{\circ} \mathrm{C}$. Blood samples were assayed for total protein content, albu$\min , \alpha_{1}, \alpha_{2}, \beta_{1}, \beta_{2}$ and $\gamma$ globulins. Immediately before the DSC measurements, each serum sample was thawed out at room temperature. Then 20 -fold diluted serum solution was prepared using the redistilled and degassed water. The $\mathrm{pH}$ values of the diluted serum samples were within the range 6.5-7.0.

\section{Differential scanning calorimetry}

DSC measurements were conducted using the VP DSC MicroCal instrument (Northampton, MA) in the temperature range $20-100{ }^{\circ} \mathrm{C}$ with the heating rate $1{ }^{\circ} \mathrm{C} \mathrm{min}^{-1}$ and a prescan equilibration time $15 \mathrm{~min}$. A constant pressure of about $1.7 \times 10^{5} \mathrm{~Pa}$ was exerted on the liquids in the cells. Two scans were obtained for every sample. The calorimetric data were corrected for the instrumental baseline water-water. DSC curves were normalized for the gram mass of protein, and next, a linear baseline was subtracted. An apparent excess specific heat capacity $\mathrm{Cp}^{\mathrm{ex}}\left(\mathrm{J}^{\circ} \mathrm{C}^{-1} \mathrm{~g}^{-1}\right)$ versus temperature $\left({ }^{\circ} \mathrm{C}\right)$ has been plotted.

The following parameters of observed DSC transitions have been determined: temperatures of local peak maxima $T_{\mathrm{m}}(m=1,2,3)$, excess specific heat capacities at these temperatures $\mathrm{Cp}_{\mathrm{m}}$, the enthalpy $(\Delta H)$ of serum denaturation (calculated as the area under the endothermic peak, expressed in $\mathrm{J} \mathrm{g}^{-1}$ ) and the width of peak in its half height (HHW).

\section{Statistical analysis}

Statistical analysis was performed using the Statistica 13 software. For all measures, descriptive statistics were calculated. To compare parameters before and after the WBC, $t$ test for dependent variables was applied. The Shapiro-Wilk test was used to check the normality of distributions of the studied variables. The homogeneity of variances in analyzed groups was verified by Leven's test. Analysis of variance (ANOVA) with the period of training cycle as a repeated measure was used. Mauchly's test for sphericity was included as a part of the procedure. If repeated measures ANOVA was statistically significant, Tukey's post hoc test was applied. The level of statistical significance was set at $p<0.05$, and results with $p<0.1$ were interpreted as tendencies.

Pearson's correlation coefficients were found to describe the relationships between biochemical and thermodynamic blood serum parameters.

\section{Results and discussion}

According to our and other previous reports [37-40, 47, $48,53-55]$, two or three relatively well-resolved thermal transitions are observed in DSC profiles of blood sera from healthy individuals, depending on the solvent used. Roughly, 
in buffer (pH 7.4) solution, peaks around $62{ }^{\circ} \mathrm{C}$ and $70{ }^{\circ} \mathrm{C}$ reflect the thermal denaturation of the most abundant serum proteins, albumin and immunoglobulis, respectively. In such solution, an un-liganded albumin unfolds in higher temperature range and its transition is more cooperative than in aqueous solution. For sera denaturation in aqueous solution, three relatively well-resolved transitions can be usually observed. The first one, at about $58{ }^{\circ} \mathrm{C}$, mainly represents the contribution from un-liganded albumin, while the third one at about $70{ }^{\circ} \mathrm{C}$, just like in buffer solutions, comes from denaturation of immunoglobulis. The sharp peak at about $62{ }^{\circ} \mathrm{C}$ is not always visible. It has its origin mainly in haptoglobin, the acute-phase protein belonging to alpha-2 globulins fraction.

Figure 1 shows the mean DSC curves of serum from blood acquired before exercise, after exercise, after an hour of rest and $24 \mathrm{~h}$ of rest before WBC treatments. It is clearly visible that the DSC curve corresponding to serum after the exercise stands out from the others. This indicates that fatigue developed during the exercise is reflected in the blood serum. The impact of the effort is manifested by opposite changes in two temperature regions of the endothermic transition: a decrease of the intensity in the low $\left(50-60^{\circ} \mathrm{C}\right)$ and an increase in the high $\left(65-80^{\circ} \mathrm{C}\right)$ temperature range. The additional effect observed after the exercise in serum DSC curves is the exothermic transition visible above $85^{\circ} \mathrm{C}$. It suggests increased aggregation of serum proteins following their endothermic unfolding. This effect persists after an hour of rest, but disappears after $24 \mathrm{~h}$ of rest.

After applying the series of $10 \mathrm{WBC}$ treatments, the calorimetric behavior of blood sera of athletes that underwent training exercises was very similar to that shown in Fig. 1. The nature of the mean changes connected with the effort and post-exercise recovery practically did not change after WBC (therefore, the results are not shown in the additional figure). Figure 2 illustrates the mean pre-exercise serum

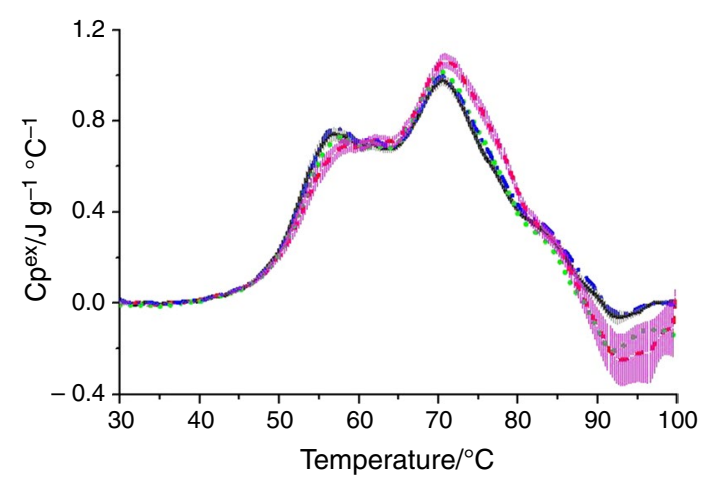

Fig. 1 Mean DSC curves of serum taken before exercise (solid black line), after exercise (dash red line), after an hour of rest (dot green line) and $24 \mathrm{~h}$ of rest (dash-dot black line) before WBC treatments; the shaded area is the standard error at each temperature (shown for "be" and "ae" curves). (Color figure online)
DSC curves before and after $10 \mathrm{WBC}$ treatments and the differences between post-exercise and pre-exercise curves in both training sessions. On first sight, some differences between mean pre-exercise DSC curves before and after 10 WBC treatments are visible, while the response to the effort, reflected in serum heat capacity changes, seems to be the same, regardless of the application of cryostimulation.

Tables 3 and 4 illustrate mean $( \pm \mathrm{SD})$ values of thermodynamic parameters in subsequent stages of the training cycle (before and after the exercise, after $1 \mathrm{~h}$ and $24 \mathrm{~h}$ of rest) conducted without WBC treatments and after $10 \mathrm{WBC}$ treatments, respectively. Statistically significant differences between parameters in both sessions have been found only for $\mathrm{Cp}_{1}$. Lower values of $\mathrm{Cp}_{1}$ have been observed both before $(p=0.02)$ and after exercise $(p=0.04)$ when cryostimulation was included.

To establish whether calorimetric parameters of serum denaturation transition reflect the effect of fatigue and the status of athletes after the rest, ANOVA with the stage of training cycle as the factor of repeated measurements was carried out. The results have indicated statistically significant differences for mean values of $T_{1}(p=0.015), \mathrm{Cp}_{1}$ $(p=0.04), T_{3}(p<0.001)$ and $\mathrm{Cp}_{3}(p=0.014)$ when the exercise was performed without WBC treatments. The post hoc Tukey's test has shown significant increase of $T_{1}(p=0.018)$, $T_{3}(p<0.001)$ and $\mathrm{Cp}_{3}(p=0.011)$ after the exercise as well as significantly lower mean value of $\mathrm{Cp}_{1}$ immediately after the exercise than after $24 \mathrm{~h}$ of rest $(p=0.034)$. Additionally, $T_{3}$ has been indicated higher after the exercise than after $1 \mathrm{~h}$ and $24 \mathrm{~h}$ recovery periods ( $p<0.001$ in both cases). Differences between parameters corresponding to exercise and recovery stages after $10 \mathrm{WBC}$ treatments are of a similar nature to these described above, but statistical significance has been found only for $\mathrm{Cp}_{1}$ between "ae" and " $24 \mathrm{~h}$ "

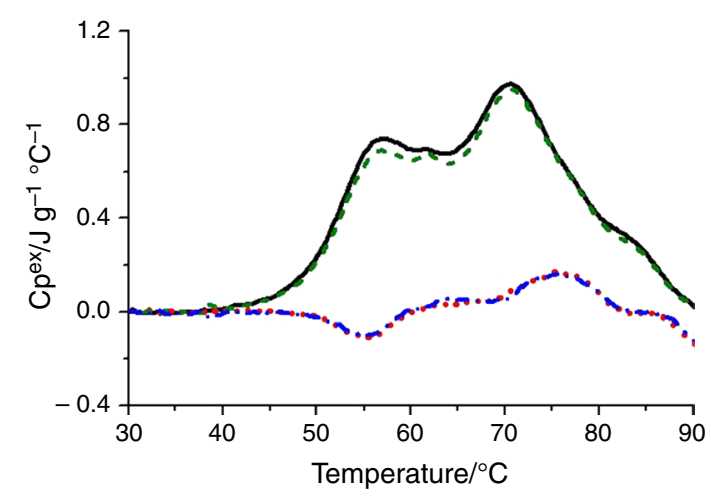

Fig. 2 Mean DSC curves of serum before exercise when the WBC was not applied (solid black line), and after a series of $10 \mathrm{WBC}$ treatments (dash green line); differences between post-exercise and before-exercise curves when the WBC was not applied (dot red line) and after a series of $10 \mathrm{WBC}$ treatments (dash-dot blue line). (Color figure online) 
Table 3 Mean $( \pm$ SD) values of thermodynamic parameters in subsequent stages of the training cycle conducted without WBC treatments: before and after the exercise, after $1 \mathrm{~h}$ and $24 \mathrm{~h}$ of rest

Table 4 Mean $( \pm \mathrm{SD})$ values of thermodynamic parameters in subsequent stages of the training cycle conducted after $10 \mathrm{WBC}$ treatments: before and after the exercise, after $1 \mathrm{~h}$ and $24 \mathrm{~h}$ of rest

\begin{tabular}{lllll}
\hline Parametr & \multicolumn{3}{l}{ Without WBC treatments } \\
\cline { 2 - 5 } & be & ae & r1 h & r24 h \\
\hline$T_{1} /{ }^{\circ} \mathrm{C}$ & $56.74 \pm 1.23$ & $58.05 \pm 1.04$ & $57.53 \pm 1.33$ & $56.93 \pm 0.82$ \\
$\mathrm{Cp}_{1} / \mathrm{J} \mathrm{g}^{-1}{ }^{\circ} \mathrm{C}^{-1}$ & $0.767 \pm 0.078$ & $0.704 \pm 0.079$ & $0.750 \pm 0.105$ & $0.779 \pm 0.079$ \\
$T_{2} /{ }^{\circ} \mathrm{C}$ & $61.82 \pm 0.61$ & $62.01 \pm 0.54$ & $61.85 \pm 0.72$ & $61.89 \pm 0.66$ \\
$\mathrm{Cp}_{2} / \mathrm{J} \mathrm{g}^{-1}{ }^{\circ} \mathrm{C}^{-1}$ & $0.700 \pm 0.067$ & $0.721 \pm 0.075$ & $0.700 \pm 0.079$ & $0.729 \pm 0.067$ \\
$T_{3} /{ }^{\circ} \mathrm{C}$ & $70.56 \pm 0.23$ & $71.11 \pm 0.44$ & $70.62 \pm 0.42$ & $70.49 \pm 0.21$ \\
$\mathrm{Cp}_{3} / \mathrm{J} \mathrm{g}{ }^{-1}{ }^{\circ} \mathrm{C}^{-1}$ & $0.976 \pm 0.063$ & $1.068 \pm 0.101$ & $1.018 \pm 0.079$ & $0.997 \pm 0.088$ \\
$\Delta H / \mathrm{J} \mathrm{g}$ & $23.76 \pm 1.42$ & $24.76 \pm 2.05$ & $23.51 \pm 2.35$ & $24.47 \pm 1.72$ \\
$\mathrm{HHW} /{ }^{\circ} \mathrm{C}$ & $25.4 \pm 1.2$ & $24.8 \pm 1.7$ & $24.6 \pm 1.4$ & $25.7 \pm 1.7$ \\
\hline
\end{tabular}

$(p=0.018)$ and for $T_{3}$ between "ae" and all other stages $(p<0.005)$.

A parameter worth analyzing is the ratio of $\mathrm{Cp} 3$ to $\mathrm{Cp} 1$. This ratio increases significantly $(p<0.01)$ after exercise in both experimental sessions, conducted before and after WBC treatments (from 1.27 to 1.52 and from 1.38 to 1.62 , respectively). Then, during the recovery $\mathrm{Cp} 3 / \mathrm{Cp} 1$ decreases and returns to the baseline value after $24 \mathrm{~h}$ if $\mathrm{WBC}$ was not applied and already after $1 \mathrm{~h}$ of rest if $\mathrm{WBC}$ was used. It seems particularly interesting that after the exercise in the training session enriched with WBC, high, statistically significant correlations occur between the $\mathrm{Cp} 3 / \mathrm{Cp} 1$ ratio and the anthropometric parameters like: height $(r=-0.84$; $p=0.009)$, skeletal muscle mass $(r=-0.8 ; p=0.018)$, body fat mass $/ \%(r=0.79 ; p=0.02)$ and body mass $(r=-0.76$; $p=0.03)$. Correlations between anthropometric characteristics of athletes and the $\mathrm{Cp} 3 / \mathrm{Cp} 1$ ratio in other stages of experiment have the same character, but they were much weaker and statistically insignificant. Such results allow to suggest the synergistic effect of exercise and whole-body cryostimulation in professional skiers. Ziemann's et al. [58] results also suggested the synergistic anti-inflammatory effect of moderate-intensity training and whole-body cryostimulation in professional athletes.

Another puzzling significant correlation (shown in Table 5) has been found between HR at the Anaerobic Threshold (HR-AT) and the $\mathrm{Cp} 3 / \mathrm{Cp} 1$ ratio in all stages
Table 5 Pearson's correlation coefficients between HR-AT and the $\mathrm{Cp} 3 / \mathrm{Cp} 1$ ratio in various stages of training session

\begin{tabular}{lllll}
\hline & be & ae & r1h & r24h \\
\hline Session with- & $-\mathbf{0 . 8 5}$ & $-\mathbf{0 . 8 1}$ & $\mathbf{- 0 . 7 6}$ & $-\mathbf{0 . 8 4}$ \\
out WBC & $\boldsymbol{p}=\mathbf{0 . 0 0 8}$ & $\boldsymbol{p}=\mathbf{0 . 0 1 4}$ & $\boldsymbol{p}=\mathbf{0 . 0 3}$ & $\boldsymbol{p}=\mathbf{0 . 0 1}$ \\
$\begin{array}{c}\text { treatments } \\
\text { Session with }\end{array}$ & $\mathbf{- 0 . 8 1}$ & -0.53 & -0.51 & -0.67 \\
WBC treat- & $\boldsymbol{p}=\mathbf{0 . 0 1 5}$ & $p=0.18$ & $p=0.20$ & $p=0.15$ \\
ments & & & &
\end{tabular}

Significant correlations $(p<0.05)$ are printed in bold

of exercise session without WBC. Negative correlations indicate that higher values of HR-AT are accompanied by lower $\mathrm{Cp} 3 / \mathrm{Cp} 1$ ratios. In the case of the session with WBC, statistically significant correlation occurs only in one stage (before exercise). We are not able reasonably interpret the found relationship.

Changes observed in the mean serum DSC profiles and trends for $\mathrm{Cp}_{1}, \mathrm{Cp}_{3}$ values suggest a decrease of albumin and an increase of gammaglobulin content after the exercise. Actually, the gammaglobulin concentration increases from $12.2 \pm 0.5 \mathrm{~g} \mathrm{~L}^{-1}$ before the exercise to $13.3 \pm 0.9 \mathrm{~g} \mathrm{~L}^{-1}$ after the exercise. This increase is on the verge of statistical significance $(p=0.05)$. However, albumin's pre-exercise level is not lower than post-exercise one. It even significantly $(p=0.01)$ grows from $42.2 \pm 0.4$ to $44.6 \pm 0.4 \mathrm{~g} \mathrm{~L}^{-1}$. 
Considering that statistically significant increase of the level of total protein in blood serum has been observed after the exercise (from $78.6 \pm 0.8$ to $84.0 \pm 1.4 \mathrm{~g} \mathrm{~L}^{-1}$ ), \% participation of albumin has practically remained unchanged. Thus, as a likely explanation one can suggest a reduction in the fraction of an un-liganded albumin with simultaneous increase of albumin with bound ligands (e.g. fatty acids). This fraction of albumin unfolds in higher temperature range, overlapping with that for gammaglobulins [59]. The meaningful seems to be the change of the character of correlation between the amount of serum albumin and $\mathrm{Cp}_{1}$ from positive before the exercise $(r=0.78 ; p=0.04)$ to negative $(r=-0.83 ; p=0.04)$ after the exercise in the training session without WBC. Physical exercise can affect the metabolite profile and the composition and content of polyunsaturated essential fatty acids in body fluids and tissues [60]. Allen et al. [61] have reported recently that exercise training alters gut microbial communities and increases functional metabolic capacity for the gut microbiota to produce short chain fatty acids (SCFA), which serve as an energy source for a variety of tissues and have been shown to reduce inflammation. These exercise-induced changes in the microbiota were largely reversed once exercise training ceased.

Although the exercise test was adjusted to participant's individual threshold intensity, the response of athletes to the effort was varied. For two men and one woman, practically no change in the DSC curves of sera after exercise was observed in the first session, i.e. without the use of WBC treatments. Thus, for a more detailed analysis, the group of athletes was divided into two subgroups. The first group consisted of athletes for whom the trends of response to effort and then rest was as it follows from the comparison of mean DSC curves illustrated in Fig. 1. The second group consisted of three skiers less responsive to the effort. For these athletes, differences between DSC curves of serum in various stages of training were hardly visible. It seems interesting to note that the woman included in this group had from the participants of the study the highest percentage of body fat (24\%), and the two men the largest \% of body fat (both $12.5 \%$ ) among men. In Fig. 3, differences in trends of post-exercise changes observed for both groups due to the use of cryotherapy are illustrated. For the group 1, the changes in serum DSC curves caused by exercise were smaller after WBC treatments while for the group 2, differences observed in the range $50-60{ }^{\circ} \mathrm{C}$, contrary to the group 1 , increased slightly under the influence of repeated systemic cryostimulation. These differences for the group 2 remained, however, so small that it would be unreasonable to interpret them. The limitation of our study is too small number of participants to verify the hypothesis that the modification of the response of elite skiers to the effort by WBC treatments depends on the athlete's obesity status. There are

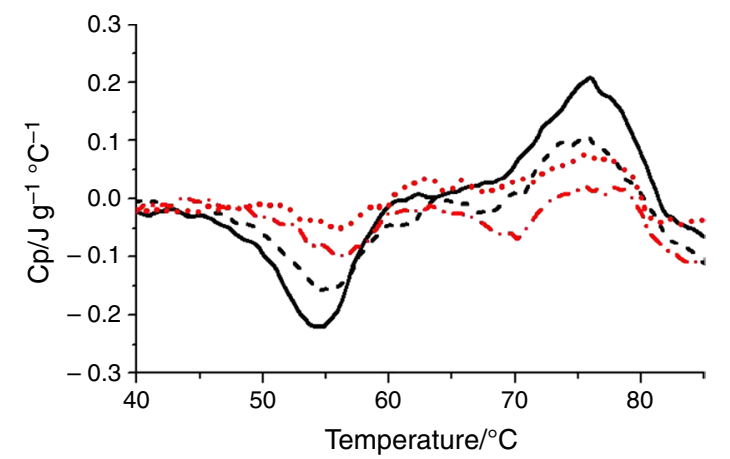

Fig. 3 Differences between post-exercise and pre-exercise mean serum DSC curves before WBC (- group 1, --- group 2) and after WBC (...g group 1,-·-- group 2). (Color figure online)

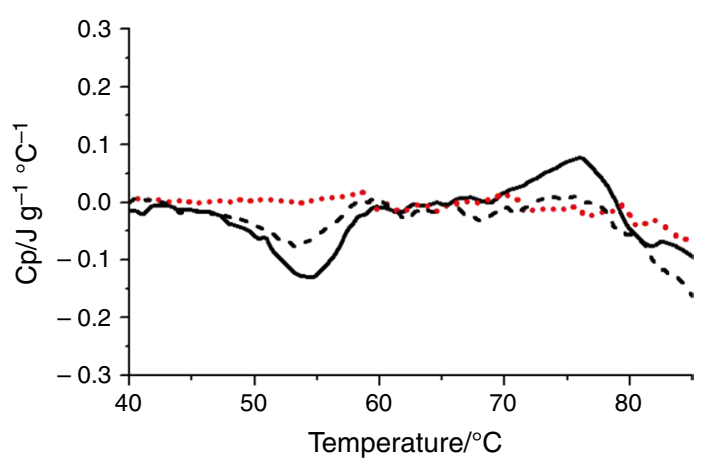

Fig. 4 Differences between "r1h" and "be" mean serum DSC curves before WBC (- group 1,.. group 2) and after WBC (--- group 1). (Color figure online)

differences in metabolic reactions to the cold between lean and over-weight people. A higher concentration of body fat percentage in women than in men determines the higher females inner thermal resistance [62]. Since only 2 women participated in our study, we are unable to infer any differences with regard to the sex of the participants. It should be also noted that none of the participants was overweight. In our earlier study [63], a decrease of $\%$ fat content after $10 \mathrm{WBC}$ was found but mainly for participants with the low level of body fat mass.

The comparison of curves shown in Fig. 4 indicates that when whole-body cryostimulation was applied in group 1, the recovery after exercise became almost fully after $1 \mathrm{~h}$ of rest. The difference in the $70-80{ }^{\circ} \mathrm{C}$ temperature range has disappeared. These findings suggest that WBC applied before exercise could be used to support and accelerate the recovery process. However, to increase the strength of these promising results, it will be necessary in future studies to enlarge the group of participants. 


\section{Conclusions}

This study was part of a larger project investigating effects of whole-body cryostimulation on exercise responses, recovery and the control of the inflammatory process after exercise in elite athletes, cellular functions, which are the basis of optimized performance of organs and the entire organism, and regulation of metabolic and hormonal pathways.

Differential scanning calorimetry was applied to evaluate the effect of WBC on the response of elite cross-country skiers to the exhaustive exercise and the recovery of athletic performance following exercise. Reflected in mean DSC curves differences among serum samples collected in four stages: before exercise, after exercise, after $1 \mathrm{~h}$ of rest and after $24 \mathrm{~h}$ of rest have been found of a similar nature regardless of the WBC. However, a diversity in the individual response both to the effort and cryostimulation has been observed. In most cases, the effect of fatigue was clearly reflected in thermal properties of blood serum. The application of WBC in these well-trained cross-country skiers modified their response to physical effort and enhanced postexercise recovery. After completing a total of ten wholebody cryostimulation sessions, the intensity of the effort response has been reduced for the majority of athletes from the studied group. Too small group of elite athletes in our study did not allow to confirm statistically significant effect of WBC on exercise-induced changes in blood serum and on post-exercise recovery.

Funding The project has been financed by the grant Ministry of Science and Higher Education/Nr 0050/RS4/2016/54.

\section{Compliance with ethical standards}

Conflict of interest The authors declare that they have no conflict of interest.

Open Access This article is licensed under a Creative Commons Attribution 4.0 International License, which permits use, sharing, adaptation, distribution and reproduction in any medium or format, as long as you give appropriate credit to the original author(s) and the source, provide a link to the Creative Commons licence, and indicate if changes were made. The images or other third party material in this article are included in the article's Creative Commons licence, unless indicated otherwise in a credit line to the material. If material is not included in the article's Creative Commons licence and your intended use is not permitted by statutory regulation or exceeds the permitted use, you will need to obtain permission directly from the copyright holder. To view a copy of this licence, visit http://creativecommons.org/licenses/by/4.0/.

\section{References}

1. Lombardi G, Ziemann E, Banfi G. Whole-body cryotherapy in athletes: from therapy to stimulation. An updated review of the literature. Front Physiol. 2017. https://doi.org/10.3389/fphys .2017.00258.

2. Lubkowska A, Banfi G, Dolegowska B, d'Eril GV, Łuczak J, Barrasi A. Changes in lipid profile in response to three different protocols of whole-body cryostimulation treatments. Cryobiology. 2010;61(1):22-6.

3. Lubkowska A, Dudzińska W, Bryczkowska I, Dołęgowska B. Body composition, lipid profile, adipokine concentration, and antioxidant capacity changes during interventions to treat overweight with exercise programme and whole-body cryostimulation. Oxidative Med Cell Longev. 2015. https://doi.org/10.1155/2015/80319 7.

4. Banfi G, Melegati G, Barassi A, Dogliotti G, d'Eril GM, Dugué $\mathrm{B}$, et al. Effects of whole-body cryotherapy on serum mediators of inflammation and serum muscle enzymes in athletes. J Therm Biol. 2009;34:55-9.

5. Hausswirth C. The effects of whole-body cryotherapy exposure in sport: applications for recovery and performance. (2015). https ://pdfs.semanticscholar.org/6523/16df7bc920a6bf47c7834f7a1 beb50dd7185.pdf. Accessed Jan 2019.

6. Schaal K, Le Meur Y, Louis J, Filliard JR, Hellard P, Casazza $\mathrm{G}$, Hausswirth C. Whole-body cryostimulation limits overreaching in elite synchronized swimmers. Med Sci Sports Exerc. 2015;47:1416-25.

7. Bouzigon R, Ravier G, Dugue B, et al. The use of whole-body cryostimulation to improve the quality of sleep in athletes during high level standard competitions. Br J Sports Med. 2014;48(7):572.

8. Rymaszewska J, Ramsey D, Chładzińska-Kiejna S. Whole-body cryotherapy as adjunct treatment of depressive and anxiety disorders. Archivum Immunologiae et Therapiae Experimentalis. 2008;56:63-8.

9. Charkoudian N. Mechanisms and modifiers of reflex induced cutaneous vasodilation and vasoconstriction in humans. $\mathbf{J}$ Appl Physiol. 2010;109(4):1221-8.

10. Manou-Stathopoulou V, Goodwin CD, Patterson T, Redwood SR, Marber MS, Williams RP. The effects of cold and exercise on the cardiovascular system. Heart. 2015;101:808-20.

11. Stocks JM, Taylor NA, Tipton MJ, Greenleaf JE. Human physiological responses to cold exposure. Aviat Space Environ Med. 2004;75(5):444-57.

12. Dugué B, Smolander J, Westerlund T, Oksa J, Nieminen R, Moilanen $\mathrm{E}$, et al. Acute and long-term effects of winter swimming and whole-body cryotherapy on plasma antioxidative capacity in healthy women. Scand J Clin Lab Invest. 2005;65(5):395-402.

13. Lubkowska A, Dolegowska B, Szygula Z, Klimek A. Activity of selected enzymes in erythrocytes and level of plasma antioxidants in response to single whole-body cryostimulation in humans. Scand J Clin Lab Invest. 2009;69:387-94.

14. Lubkowska A, Szygula Z, Klimek AJ, Torii M. Do sessions of cryostimulation have influence on white blood cell count, level of IL6 and total oxidative and antioxidative status in healthy men? Eur J Appl Physiol. 2010;109:67-72.

15. Stanek A, Sieroń-Stołtny K, Romuk E, et al. Whole-body cryostimulation as an effective method of reducing oxidative stress in healthy men. Adv Clin Exp Med. 2016;25:1281-91.

16. Stanek A, Cholewka A, Wielkoszyński T, Romuk E, Sieroń A. Whole-body cryotherapy decreases the levels of inflammatory, oxidative stress, and atherosclerosis plaque markers in male patients with active-phase ankylosing spondylitis in the absence of classical cardiovascular risk factors. Hindawi Mediat Inflamm. 2018. https://doi.org/10.1155/2018/8592532. 
17. Pournot H, Bieuzen F, Louis J, Mounier R, Fillard JR, Barbiche E. Time-course of changes in inflammatory response after wholebody cryotherapy multi exposures following severe exercise. PLoS ONE. 2011. https://doi.org/10.1371/annotation/0adb3312-7d2b459c-97f7-a09cfecf5881.

18. Wozniak A, Wozniak B, Drewa G, Mila-Kierzenkowska C, Rakowski A. The effect of whole-body cryostimulation on lysosomal enzyme activity in kayakers during training. Eur J Appl Physiol. 2007;100:137-42.

19. Ziemann E, Olek RA, Grzywacz T, Kaczor JJ, Antosiewicz J, Skrobot W, Kujach S, Laskowski R. Whole-body cryostimulation as an effective way of reducing exercise-induced inflammation and blood cholesterol in young men. Eur Cytokine Netw. 2014;25:14-23.

20. Fonda B, Sarabon N. Effects of whole-body cryotherapy on recovery after hamstring damaging exercise: a crossover study. Scand J Med Sci Sports. 2013;23:e270-8.

21. Hausswirth C, Louis J, Bieuzen F, Pournot H, Fournier J, Filliard JR, Brisswalter J. Effects of whole-body cryotherapy vs. far-infrared vs. passive modalities on recovery from exerciseinduced muscle damage in highly-trained runners. PLoS ONE. 2011. https://doi.org/10.1371/journal.pone.0027749.

22. Mila-Kierzenkowska C, Jurecka A, Wozniak A, Szpinda M, Augustynska B, Wozniak B. The effect of submaximal exercise preceded by single whole-body cryotherapy on the markers of oxidative stress and inflammation in blood of volleyball players. Oxidative Med Cell Longev. 2013. https://doi. org/10.1155/2013/409567.

23. Krueger M, Costello JT, Achtzehn S, Dittmar KH, Mester J. Whole-body cryotherapy $(-110$ \& \#xB0;C) following high-intensity intermittent exercise does not alter hormonal, inflammatory or muscle damage biomarkers in trained males. Cytokine. 2019. https://doi.org/10.1016/j.cyto.2018.07.018.

24. Costello JT, Algar LA, Donnelly AE. Effects of whole-body cryotherapy $(-110 \& \# \mathrm{xB} 0 ; \mathrm{C})$ on proprioception and indices of muscle damage. Scand J Med Sci Sports. 2012;22:190-8.

25. Vieira A, Bottaro M, Ferreira-Junior JB, Vieira C, Cleto VA, Cadore EL, Simoes HG, Carmo JD, Brown LE. Does wholebody cryotherapy improve vertical jump recovery following a high-intensity exercise bout? Open Access J Sports Med. 2015;6:49-54

26. Wilson LJ, Cockburn E, Paice K, Sinclair S, Faki T, Hills FA, Gondek MB, Wood A, Dimitriou L. Recovery following a marathon: a comparison of cold water immersion, whole body cryotherapy and a placebo control. Eur J Appl Physiol. 2018;118(1):153-63.

27. Costello JT, Baker PRA, Minett GM, Bieuzen F, Stewart IB, Bleakley C. Whole-body cryotherapy (extreme cold air exposure) for preventing and treating muscle soreness after exercise in adults. Cochrane Database Syst Rev. 2015;9:CD010789. https ://doi.org/10.1002/14651858.cd010789.pub2.

28. Dupuy O, Douzi W, Theurot D, Bosquet L, Dugué B. An evidence-based approach for choosing post-exercise recovery techniques to reduce markers of muscle damage, soreness, fatigue, and inflammation: a systematic review with meta-analysis. Front Physiol. 2018. https://doi.org/10.3389/fphys.2018.00403.

29. Kruger M, de Marees M, Dittmar KH, Sperlich B, Mester J. Whole-body cryotherapy's enhancement of acute recovery of running performance in well-trained athletes. Int J Sports Physiol Perform. 2015;10:605-12.

30. Minett GM, Costello JT. Specificity and context in post-exercise recovery: it is not a one-size-fits-all approach. Front Physiol. 2015. https://doi.org/10.3389/fphys.2015.00130.

31. Dufour SP, Lampert E, Doutreleau S, Lonsdorfer-Wolf E, Billat VL, Piquard F, Richard R. Eccentric cycle exercise: training application of specific circulatory adjustments. Med Sci Sports Exerc. 2014;36(11):1900-6.

32. Perrey S, Betik A, Candau R, Rouillon JD, Hughson RI. Comparison of oxygen uptake kinetics during concentric and eccentric cycle exercise. J Appl Physiol. 2001;91(5):2135-42.

33. Pokora I, Grucza R. Reakcje termoregulacyjne podczas koncentryczego, ekscentrycznego i mieszanego wysiłku biegowego. Medicina Sportiva Practica. 2007;8(4):107-10.

34. McCully KK, Faulkner JA. Characteristics of lengthening contractions associated with injury to skeletal muscle fibers. J Appl Physiol. 1986;61(1):293-9.

35. Sorichter S, Martin M, Julius P, Schwirtz A, Huonker M, Luttmann W, Walterspacher S, Berg A. Effects of unaccustomed and accustomed exercise on the immune response in runners. Med Sci Sports Exerc. 2006;38:1739-45.

36. Pokora I, Kempa K, Chrapusta SJ, Langfort J. Effects of downhill and uphill exercises of equivalent submaximal intensities on selected blood cytokine levels and blood creatine kinase activity. Biol Sport. 2014;31(3):173-8.

37. Garbett NC, Miller JJ, Jenson AB, Chaires JB. Calorimetry outside the box: a new window into the plasma proteome. Biophys J. 2008;94:1377-83.

38. Garbett NC, Mekmaysy CS, Helm W, Jenson AB, Chaires JB. Differential scanning calorimetry of blood plasma for clinical diagnosis and monitoring. Exp Mol Pathol. 2009;86:186-91.

39. Michnik A, Drzazga Z, Michalik K, Barczyk A, Santura I, Sozańska E, Pierzchała W. Differential scanning calorimetry study of blood serum in chronic obstructive pulmonary disease. J Therm Anal Calorim. 2010;102:57-60.

40. Todinova S, Krumova S, Gartcheva L, Robeerts Ch, Taneva SG. Microcalorimetry of blood serum proteome: a modified interaction network in the multiple myeloma case. Anal Chem. 2011;83:7992-8.

41. Zapf I, Fekecs T, Ferencz A, Tizedes G, Pavlovics G, Kálmán E, Lörinczy D. DSC analysis of human plasma in breast cancer patients. Thermochim Acta. 2011;524:88-91.

42. Fekecs T, Zapf I, Ferencz A, Lörinczy D. Differential scanning calorimetry (DSC) analysis of human plasma in melanoma patients with or without regional lymph node metastases. J Therm Anal Calorim. 2012;108:149-52.

43. Todinova SJ, Krumova SB, Kurtev P, Dimitrov V, Djongov L, Dudunkov Z, Taneva SG. Calorimetry-based profiling of blood plasma from colorectal cancer patients. Biochim Biophys Acta. 2012;820:1879-85.

44. Moezzi M, Fekecs T, Zpf I, Ferencz A, Lörinczy D. Differential scanning calorimetry (DSC) analysis of human plasma in different psoriasis stages. J Therm Anal Calorim. 2013;111:1801-4.

45. Garbett NC, Merchant ML, Helm CW, Jenson AB, Klein JB, Chaires JB. Detection of cervical cancer biomarker patterns in blood plasma and urine by differential scanning calorimetry and mass spectrometry. PLoS ONE. 2014. https://doi.org/10.1371/ journal.pone.0084710.

46. Todinova S, Krumova S, Radoeva R, Gartcheva L, Taneva SG. Calorimetric markers of Bence Jones and nonsecretory multiple myeloma serum proteome. Anal Chem. 2014;86:12355-61.

47. Garbett NC, Mekmaysy CS, DeLeeuw L, Chaires JB. Clinical application of plasma thermograms. Utility, practical approaches and considerations. Methods. 2015;76:41-50.

48. Barceló F, Cerdà JJ, Gutiérrez A, Jimenez-Marco T, Durán MA, Novo A, et al. Characterization of monoclonal gammopathy of undetermined significance by calorimetric analysis of blood serum proteome. PLoS ONE. 2015. https://doi.org/10.1371/ journal.pone.0120316.

49. Zapf I, Moezzi MM, Fekecs T, Nedvig K, Lőrinczy D, Ferencz A. Influence of oxidative injury and monitoring of blood 
plasma by DSC on breast cancer patients. J Therm Anal Calorim. 2016;123:2029-35.

50. Nemsadze GS, Lezhava TA, Gorgoshidze MZ, Kiladze M, Gogelia N, Khachidze D, Lomidze E, Monaselidze J. Blood plasma main proteins stability of patients with ductal carcinoma in postsurgery period. Int J Clin Exp Med. 2016;9:1338-45.

51. Ferencz A, Lorinczy D. DSC measurements of blood plasma on patients with chronic pancreatitis and operable and inoperable pancreatic adenocarcinoma. J Therm Anal Calorim. 2017; 127:1187-92.

52. Wiegand N, Bücs G, Dandé LD. Investigation of protein content of synovial fluids with DSC in different arthritides. J Therm Anal Calorim. 2019. https://doi.org/10.1007/s10973-019-08151-6.

53. Michnik A, Drzazga Z, Poprzęcki S, Czuba M, Kempa K, Sadowska-Krępa E. DSC serum profiles of sportsmen. J Therm Anal Calorim. 2013;113:365-70.

54. Michnik A, Sadowska-Krępa E, Domaszewski P, Duch K, Pokora I. Blood serum DSC analysis of well-trained men response to CrossFit training and green tea extract supplementation. J Therm Anal Calorim. 2017;130:1253-62.

55. Michnik A, Drzazga Z, Schisler I, Poprzęcki S, Czuba M. Diversity in athlete's response to strength effort in normobaric hypoxia. Serum DSC study. J Therm Anal Calorim. 2018;134:633-41.

56. Czuba M, Maszczyk A, Gerasimuk D, Roczniok R, Fidos-Czuba O, Zając A, Gołaś A, Mostowik A, Langfort J. The effects of hypobaric hypoxia on erythropoiesis, maximal oxygen uptake and energy cost of exercise under normoxia in elite biathletes. J Sports Sci Med. 2014;13(4):912-20.

57. Cheng B, Kuipers H, Snyder AC, Keizer HA, Jeukendrup A, Hesselink M. A new approach for the determination of ventilatory and lactate thresholds. Int J Sports Med. 1992;13(7):518-22.
58. Ziemann E, Olek RA, Kujach S, Grzywacz T, Antosiewicz J, Garsztka T, Laskowski R. Five-day whole-body cryostimulation, blood inflamantory markers, and performance in high-ranking professional tennis players. J Athletic Train. 2012;47(6):664-72.

59. Michnik A, Drzazga Z. Thermal denaturation of mixtures of human serum proteins-DSC study. J Therm Anal Calorim. 2010;101:513-8.

60. Chorell E, Svensson MB, Moritz T, Antti H. Physical fitness level is reflected by alterations in the human plasma metabolome. Mol BioSyst. 2012;8(4):1187-96.

61. Allen JM, Mailing LJ, Niemiro GM, Moore R, Cook MD, White BA, Holscher HD, Woods JA. Exercise alters gut microbiota composition and function in lean and obese humans. Med Sci Sports Exerc. 2018;50(4):747-57.

62. Polidori G, Cuttell S, Hammond L, Langdon D, Legrand F, Taiar R, Boyer FC, Costello JT. Should whole body cryotherapy sessions be differentiated between women and men? A preliminary study on the role of the body thermal resistance. Med Hypotheses. 2018;120:60-4.

63. Duch K, Michnik A, Pokora I, Sadowska-Krępa E, Kiełboń A. Whole-body cryostimulation impact on blood serum thermal denaturation profiles of cross-country skiers. J Therm Anal Calorim. 2019. https://doi.org/10.1007/s10973-019-08766-9.

Publisher's Note Springer Nature remains neutral with regard to jurisdictional claims in published maps and institutional affiliations. 